\title{
A EDUCAÇÃO PELA LINGUAGEM EM PERTO DO CORAÇÃO SELVAGEM E A MAÇÃ NO ESCURO
}

\section{Mona Lisa Bezerra Teixeira}

\author{
Universidade de São Paulo (USP)
}

\section{RESUMO}

Em Perto do coração selvagem e A maçã no escuro, os protagonistas oscilam entre a aproximação junto a outros indivíduos e o isolamento, como uma espécie de exercício de aprendizagem diante da existência. E nesse processo de educação dramático, a linguagem é muitas vezes expressa de maneira contraventora. Joana e Martim nunca estão satisfeitos com os questionamentos que fazem e tampouco com as respostas que alcançam. Mas suas trajetórias de angústia evidenciam, sob várias nuances, o desamparo da condição humana, tão bem representado pela forma do romance.

\section{ABSTRACT}

In Near to the wild heart and The apple in the dark, the protagonists oscillate between the approach with other individuals and the isolation, like a kind of exercise of learning before the existence. And in this process of dramatic education, language is often expressed in a way transgressive. Joana and Martim are never satisfied with the questions they ask and so little with the answers they reach. But his trajectories of anxiety show, under various nuances, the helplessness of the human condition, so well represented by the form of the novel.

\section{PALAVRAS-CHAVE:}

Clarice Lispector;

Romance e aprendizagem;

Linguagem e indivíduo;

Memória e imaginação;

Literatura brasileira;

Teoria do romance.

KEYWORDS:

Clarice Lispector;

Romance and learning;

Language and individual;

Memory and imagination;

Brazilian Literature;

Theory of the novel. 
$\mathrm{A}$

reflexão crítica a respeito do romance e de sua forma esteve vinculada a uma trajetória, desde os seus primórdios até as primeiras décadas do século XX, ligada à realidade objetiva, configurada em ambientes e espaços geográficos precisos e com personagens bem delimitados. Aspectos históricos, personagens baseadas em figuras reais, peripécias envolvendo viagens, guerras e disputas pelo poder predominaram por um período significativo de expansão do romance, privilegiando, na maioria das abordagens, o foco em uma detalhada trajetória cronológica do indivíduo, expondo fases de sua vida. Mas escritores como James Joyce, Virgínia Woolf, Franz Kafka e William Faulkner deram expressão às inquietações da modernidade com um modo de narrar mais próximo à intimidade e ao imaginário do indivíduo comum, distante de grandes feitos e preso a amarras insólitas da realidade.

Com relação ao Brasil, no período dos anos 30 e no começo da década de 40 alguns escritores como Dyonélio Machado, Lúcio Cardoso e Graciliano Ramos produziram romances que apresentaram de modo mais denso a interioridade de suas personagens, como se prenunciassem $o$ advento da obra de Clarice Lispector, cujo primeiro romance, Perto do coração selvagem, em 1943, realizou uma busca obsessiva pela manifestação plena das palavras, seja no plano da consciência, seja na perspectiva da lida com o real.

A personagem Joana, na obra citada, como também Martim, em $A$ maçã no escuro, o quarto romance da escritora, publicado em 1961, são representações de uma estética baseada na linguagem que tudo quer dizer e que pretende expandir a condição humana para além de um circuito de comunicação baseado no uso da língua de maneira uniforme e esquematizada. A ausência de diálogos em boa parte de suas narrativas, a alternância radical do tempo cronológico, assim como o enfoque no sujeito coagido diante da existência e das normas reguladoras de comportamento, reforçam uma espécie de busca incessante para entender a nossa condição diante do mundo.

Benedito Nunes, em "O mundo imaginário de Clarice Lispector"1, no tópico sobre "A estrutura dos personagens", observa que Martim e Joana se aproximam pela transcendência dos nexos objetivos, sociais e históricos estabelecidos, para revelarem uma força dominadora, primitiva

1 NUNES, Benedito. O dorso do tigre. São Paulo: Editora 34, 2009, p. 115.

147 | D O S S I E : ROMANCE DE FORMAÇ̃̃O - CAMINHOS E DESCAMINHOS DO HERÓI 
e caótica diante dos outros indivíduos e dos espaços que os envolvem. Partindo dessa constatação do crítico, é possível pensar em um outro aspecto que tem presença significativa no percurso dos protagonistas desses romances: a presença da palavra como extensão das suas existências. A aprendizagem, a formação sempre incompleta de suas trajetórias ocorre pela expressão, muitas vezes incomum, da fala, como também se manifesta pela carência do diálogo. Essa combinação resulta em personagens que estão mais além de certos traços psicológicos e representações de comportamentos inseridos em uma estrutura social delimitada, pois revelam nas suas histórias, como condição humana, o fardo e a felicidade de nomear as coisas.

Joana, desde menina, inventa palavras, pergunta sobre o significado dos nomes, questiona, ainda criança, o princípio da ideia de felicidade: "Ser feliz é para se conseguir o quê?", pergunta desorientando a professora. Um outro aspecto característico dessa narrativa, que tanto ressalta o nominar, é a estruturação dos capítulos, que apresenta seus títulos sem identificar nomes próprios: "O pai", "A tia", "A mulher da voz", "O professor", "O homem". Todos esses indivíduos terão posições significativas na formação e na aprendizagem de Joana. Com relação ao pai, que é nomeado somente assim, ele é a figura mais presente nos primeiros anos de sua vida, anos fundamentais para a aquisição da linguagem e interação social, mas devido ao trabalho solitário deste, sempre à máquina de escrever, a menina fica entregue por conta própria à descoberta do poder inventivo do uso da palavra, quando, por exemplo, dá voz aos seus brinquedos, interagindo com esses objetos que só criam vida a partir da sua interferência.

No primeiro e terceiro capítulos, que retratam a sua infância, Joana observa o espaço da casa e interage com ele numa espécie de escola solitária, frente à convivência com o pai sempre atarefado. Ela inicia o seu aprendizado fantasiando com os seus brinquedos, observando o quintal do vizinho onde estavam as galinhas-que-não-sabiam-que-iam-morrer, imaginando a boneca Arlete morrer ao ser atropelada. Esses traços revelam um contato com a realidade trágica de sua condição sem a mãe, que já estava morta. Joana, como toda criança em seu divertimento, pode matar e dar vida aos objetos, movimento extraordinário da imaginação que já não pode realizar com a figura materna. No capítulo "A mãe", ela irá escutar a conversa do pai com um amigo:

Chamava-se... - olhou para Joana - chamava-se Elza. Me lembro que até lhe disse: Elza é um nome como um saco vazio [...] E mesmo aquela cor seca felizmente a guria não puxou, -, aquela cor não combinava com uma camisola...[...] Ela não precisava de mim. Nem eu dela, é verdade. Mas 
vivíamos juntos. O que eu ainda agora queria saber, dava tudo para saber, é o que ela tanto pensava. ${ }^{2}$

Contrariando o que desejava o pai, Joana terá a mesma sina da mãe. E vai percorrer um caminho de experiências da infância à vida adulta, sempre demonstrando inquietude e insatisfação diante do convívio com outros indivíduos. Não há paz na sua existência. O seu conjunto de ações durante o romance será pautado pela contestação no ambiente escolar, nas relações familiares, no casamento com Otávio, nas formalidades sociais e até mesmo nas suas transgressões, pois o contato com "o homem" realizase alheio às expectativas amorosas do senso comum, uma vez que Joana não vivencia a relação em um plano de idealização da figura masculina, limitando sua aventura a um laboratório com o sexo oposto, para ouvir suas histórias e observar o seu comportamento, o seu envolvimento com outra mulher. E em cada uma das partes do romance o modo de se expressar da personagem nos diálogos evidencia a sua personalidade argumentativa, como nos capítulos "Otávio", seu marido, e "A víbora":

- Sim, eu sei, continuava Joana. A distância que separa os sentimentos das palavras. Já pensei nisso. E o mais curioso é que no momento em que tento falar não só não exprimo o que sinto como o que sinto se transforma lentamente no que eu digo. Ou pelo menos o que me faz agir não é, seguramente, o que eu sinto mas o que eu digo. (p. 95).

- Quando eu me aproximei, disse ele sardônico, pensava que você ia me ensinar alguma coisa a mais do que isso. Eu precisava, prosseguiu mais baixo, daquilo que adivinhava em você e que você sempre negou. (p. 179).

Como observou Antonio Candido em "Uma tentativa de renovação" 3 , a autora inicia sua carreira literária dando continuidade às inovações manifestadas por nomes como Oswald de Andrade e Mário de Andrade, com relação à exploração estilística da língua portuguesa. Para o crítico, até aquele momento na literatura brasileira, os romancistas não haviam encontrado "a verdadeira exploração vocabular, a verdadeira aventura de expressão", conformando-se a padrões já estabelecidos. Sendo assim, Clarice Lispector o surpreende por evidenciar processos mentais de assimilação e reelaboração da língua na composição de sua protagonista, Joana:

\footnotetext{
2 LISPECTOR, Clarice. Perto do coração selvagem. Rio de Janeiro: Rocco, 1998, p. 27-28.

3 CANDIDO, Antonio. Brigada ligeira. São Paulo: Ed. Unesp, 1992, p. 93-102. Esse ensaio, publicado originalmente em duas partes no jornal Folha da Manhã, em 1944, também esteve presente nas primeiras edições de Vários escritos (1970), com algumas supressões, sob o título "No raiar de Clarice Lispector".
} 
Com efeito, este romance é uma tentativa impressionante de levar a nossa língua canhestra para domínios pouco explorados, forçando-a a adaptar-se a um pensamento cheio de mistério, para o qual, se sente, a ficção não é um exercício ou aventura afetiva, mas um instrumento real do espírito, apto a nos fazer penetrar em alguns dos labirintos mais retorcidos da mente. (p. 98).

Para Candido, a trajetória de Joana se configura perante um caminho que tem como objetivo evidenciar mais a essência do que a existência, mais o ser do que o estar, dando ênfase ao tempo psicológico - o que permite ao crítico qualificar Perto do coração selvagem como um "romance de aproximação". Constata que há um ritmo de procura, e para isso os vocábulos abandonam o seu sentido usual para se ajustarem "às necessidades de uma expressão muito sutil e muito tensa". Daí o caráter dramático de sua linguagem expressiva.

A aprendizagem da personagem acontece pela impossibilidade de completude, o que a aproxima da condição da língua, fonte inesgotável de sentido e formulação, além de conduzi-la sempre adiante do sentido gramatical padrão utilizado pelos outros indivíduos. E, como está dito na narrativa, "as palavras são seixos rolando nos rios", mas Joana também as inventa, e mesmo em silêncio não consegue se desvincular de uma espécie de compulsão verbal e da aflição diante do que está por vir:

- Palavras muito puras, gotas de cristal. Sinto a forma brilhante e úmida debatendo-se diante de mim. Mas onde está o que quero dizer, onde está o que devo dizer? (p. 69).

A configuração de Joana dentro da narrativa é sempre de distanciamento diante dos outros personagens mesmo quando estão no mesmo espaço físico, como no período em que convive com os parentes após a morte de seu pai. O ambiente descrito é sufocante, com o tio sempre preocupado com os seus negócios e a tia vivendo em função das aparências sociais. Mas contrariando uma posição de gratidão a esses familiares, devido a sua condição de menoridade, que a torna incapacitada para gerir a herança do pai, ela não se mostra subjugada e os enfrenta até o momento de ser mandada para o internato:

O tio e a tia já estavam à mesa. Mas a quem deles ela diria: tenho cada vez mais força, estou crescendo, serei moça? Nem a eles, nem a ninguém. Porque também a nenhum poderei perguntar: diga-me, como são as coisas? e ouvir: também não sei, como o professor respondera. (p. 61).

Nos momentos em que o período da vida escolar é retratado, Joana se enxerga numa condição de superioridade com relação às suas colegas: ela comanda as ações do grupo e revela "maturidade" ao interpretar uma linguagem de expressões faciais, sob sua concepção, a respeito de algumas 
pessoas ao redor, como no momento cômico em que as outras meninas, ingenuamente, mostram-se admiradas com sua capacidade de adivinhar o comportamento daqueles desconhecidos:

- Olhem aquele homem... Toma café com leite de manhã, bem devagar, molhando o pão na xícara, deixando escorrer, mordendo-o, levantando-se depois pesado, triste...

[...]

As colegas riam, mas aos poucos nascia alguma coisa de inquieto, doloroso e incômodo na cena. (p. 146).

Como observa Antonio Candido: assim como a vida, Perto do coração selvagem é um romance de relação, mesmo que Joana insista no seu isolamento e na sua força de exceção, afirmando: "Eu posso tudo". Na verdade, ela nada pode, pois "os outros vivem mais do que ela, porque são capazes de se esquecerem" 4 . Essa afirmação do crítico é muito instigante pelo fato de destacar a condição de Joana com relação aos demais personagens, que reprimem suas experiências mal vividas e outras situações de angústia. Mas Joana está fadada ao desassossego porque parece não desejar esquecer nada do que viveu, seja pelo pensamento compulsivo vinculado à imaginação, seja na transformação desse pensamento em palavras que sempre controvertem. Não há descanso em seu caminho, o passado é sempre retomado, o presente está sempre em embate com suas fantasias, e quanto ao futuro, que encerra a narrativa no último capítulo, "A viagem", o tormento dessa linguagem, que quanto mais tem mais quer, vai continuar.

Em A maçã no escuro 5 , preso a essas mesmas inquietações, em comunhão com o plano das ideias e da presença da linguagem como um fator de aprendizagem, Martim, o único protagonista masculino nos romances da autora, talvez seja o personagem mais dinâmico nas narrativas de Clarice Lispector. A sua história começa a ser contada a partir de sua fuga, após ter cometido um crime, delito que será revelado quase ao final da narrativa. $O$ personagem tem como objetivo esquecer o seu passado, buscando uma outra existência através de disfarces e comportamentos sobre os quais ele acredita ter controle, o que mais adiante se mostrará como uma expectativa frustrada. Como Joana, Martim no decorrer dos acontecimentos vai revelar sua personalidade solitária, mesmo quando interage com outras pessoas.

Nos romances de formação (Bildungsroman) 6 , o caminho percorrido pelo herói começa da infância e se estende até à maturidade. Existe um

\footnotetext{
${ }^{4}$ CANDIDO, Antonio. Brigada ligeira. São Paulo: Ed. Unesp, 1992. p. 100-101.

${ }^{5}$ LISPECTOR, Clarice. A maçã no escuro. Rio de Janeiro: Rocco, 1998.

${ }^{6}$ Termo divulgado por Karl Morgenstern em 1803, e utilizado para qualificar, destacadamente, a obra de Goethe, Os anos de aprendizagem de Wilhelm Meister - ver discussão e histórico detalhado
} 
predomínio da presença de mentores, de localidades circunscritas, de personagens que se movimentam no enredo de maneira relevante, impulsionando ou retendo as ações do protagonista. Mas acima de tudo, a formação desses indivíduos se dá através da experiência, dos tormentos e júbilos que envolvem a existência. Em meio a isso, os romancistas, através da ficção, acabam revelando mecanismos da sociedade à qual pertenciam, padrões de comportamento e a face histórica do seu tempo. Além dos romances alemães como Os anos de aprendizagem de Wilhelm Meister, obras como David Copperfield e As aventuras de Huckleberry Finn podem ser associadas a esses aspectos.

Vemos, assim, que as características do que poderia ser um romance de formação em Clarice Lispector são revertidas da exterioridade do real para dentro de uma "tentativa de renovação" (Antonio Candido) da linguagem. Em A maçã no escuro, a narrativa começa em um ritmo de peripécia, numa noite qualquer de março, com o personagem principal, Martim, fugindo de um hotel, depois de suspeitar que o dono do local, cismado com o seu comportamento arredio, teria ido denunciá-lo à polícia. Há duas semanas em fuga, agora o homem era "O único próprio ponto de partida". Avançava caminhando terra adentro, mas com o intuito de alcançar o mar, e nesse percurso chega a um campo vasto coberto de pedras. Nele acontece uma espécie de aprendizagem autossuficiente, pois o homem, que "a vida inteira tivera medo de um dia levar uma queda numa ocasião solene", tenta criar uma nova maneira de conduzir sua existência no campo da linguagem, sem ater-se às normas de convívio social. Para Martim é preciso elaborar uma nova existência que possibilite uma vivência distanciada de seu passado. Essa condição imaginada pelo personagem, pode ser aproximada, dentro do foco narrativo do romance de Clarice Lispector, do que diz Theodor Adorno em seu ensaio "Posição do narrador no romance contemporâneo" 7 :

O momento antirrealista do romance moderno, sua dimensão metafísica, amadurece em si mesmo pelo seu objeto real, uma sociedade em que os homens estão apartados uns dos outros e de si mesmos. Na transcendência estética reflete-se o desencantamento do mundo. (p. 58).

Nessa travessia solitária, Martim captura um passarinho, que consegue fugir por alguns instantes, mas depois é novamente aprisionado pelas mãos do homem. Sem soltá-lo, começa a dialogar com o animal, com as pedras, e também consigo, parecendo moldar-se à natureza para se

sobre a complexidade do tema em: MAZZARI, Marcus Vinicius. Metamorfoses de Wilhelm Meister: $O$ verde Henrique na tradição do Bildungsroman. In: Labirintos da aprendizagem. Pacto fáustico, romance de formação e outros temas de literatura comparada. São Paulo: Editora 34, 2010, p. 93-158.

7 ADORNO, Theodor W. Notas de literatura. São Paulo: Editora 34, 2003.

152 | D O S S I Ê : ROMANCE DE FORMAÇ̃̃O - CAMINHOS E DESCAMINHOS DO HERÓI 
expressar sem censura, e diz não saber mais falar, que perdeu a linguagem dos outros. E, assim, "com enorme coragem, aquele homem deixara enfim de ser inteligente". Desaprendendo a viver sob um mundo ambientado em linguagens estandardizadas e de imitação, agora ele reflete sobre a fuga com o peso da liberdade, pois vale salientar que o modo como Clarice Lispector elabora as manifestações de liberdade de Martim não é revestido de sensações harmoniosas - pelo contrário, como Joana durante sua jornada de conhecimento, sua rotina é obsedante:

"Na verdade", pensou então experimentando com cuidado esse truque de defesa, "na verdade apenas imitei a inteligência assim como poderia nadar como um peixe sem o ser!" [...]. Na verdade, concluiu então muito interessado, apenas imitara a inteligência com aquela falta essencial de respeito que faz com que uma pessoa imite. E com ele, milhões de homens que copiavam com enorme esforço a ideia que se fazia de um homem, ao lado de milhares de mulheres que copiavam atentas a ideia que se fazia de mulher e milhares de pessoas de boa vontade copiavam com esforço sobrehumano a própria cara e a ideia de existir [...]. Mas tão distanciados estamos pela imitação que aquilo que ouvimos nos vem tão sem som como se fosse uma visão que fosse tão invisível como se estivesse nas trevas que estas são tão compactas que mãos são inúteis. Porque mesmo a compreensão, a pessoa imitava. A compreensão que nunca fora feita senão da linguagem alheia e de palavras. (p. 34).

Rejeitando a linguagem dos outros, e tentando elaborar a sua linguagem própria, Martim nomeia o sentido da palavra crime, não mais como uma infração, delito ou falta imputáveis, mas como um gesto de coragem, de rebeldia e libertação: o seu "grande pulo", "a espantada vitória". Com essa única ação ele fez os inimigos que desejava ter: os outros. Agora, no intento de construir outra consciência, não poderia se comportar como antes, pois, se fizesse isso, ele seria seu próprio inimigo, "uma vez que na linguagem de que até então vivera ele simplesmente não poderia ser amigo de um criminoso" (p. 36).

Nessa primeira parte do romance, com o título "Como se faz um homem", o passado vai sendo revelado, muito mais a partir de suas reflexões do que propriamente por uma sequência de fatos rememorados. Evidencia-se que ele pretende esquecer as anterioridades e tencionar-se para o futuro, mas, ainda preso à tradição da trajetória romanesca, agora acirrada, o herói não tem controle sobre o seu destino. Durante um curto espaço de tempo, quando está à solta no "deserto de pedras", Martim assume uma altivez que logo será suprimida ao chegar à propriedade de Vitória. Neste local, depois de muita insistência com a dona da fazenda, emprega-se fazendo trabalhos braçais, mesmo dizendo, para o espanto da mulher, ser engenheiro. Assim começa o seu estranho convívio com os outros moradores do lugar. 
Daí, sua aprendizagem se dará no contato que terá com os animais, nos diálogos com Vitória e Ermelinda, e diante de todas as atividades que terá de fazer no local. O espaço decadente e mal cuidado da fazenda será a sua nova escola. E da labuta com a enxada aos cuidados com as plantas, da colocação de cercas à limpeza do curral, o homem terá que fazer tudo sozinho. E, nesses instantes, o silêncio se apresenta como uma espécie de linguagem:

E se a visibilidade atingia o terreno, revelavam-se folhas mortas se decompondo, pardais que se confundiam com o chão como se fossem feitos de terra [...] A planta grudava uma boca no chão [...] E o sentido daquilo era o sentido mais primeiro daquele homem. (p. 82-83).

Martim vivencia as experiências temporais e espaciais de maneira distinta dos outros moradores da fazenda, que parecem estar tão acostumados a uma ligação com a natureza que não a observam mais. Quando o lugar é descrito, é possível notar que a estrutura física da fazenda está deteriorada, mas a natureza que a envolve é vicejante. Isso será notado pelo homem, que fará desta última uma aliada para suportar o silenciamento a respeito de sua verdadeira identidade.

Ernest Cassirer em 'O mundo humano do espaço e do tempo" 8 , considera que há dois níveis de experiências relacionadas ao espaço. A primeira estaria relacionada ao espaço orgânico, característico de seres vivos menos desenvolvidos intelectualmente. Mas dentro desse espaço orgânico há o "espaço de ação", em que os animais, por exemplo, por sua natureza instintiva, são superiores ao homem. A segunda experiência estaria relacionada ao espaço perceptual, característico da diversidade de sentidos: óptico, táctil, cinestésico, acústico. Nesse aspecto, o homem supera as limitações orgânicas através da capacidade de pensar, e é pelo pensamento que o ser humano alcança a ideia de um espaço abstrato, extrapolando a compreensão da existência apenas pela relação com os objetos sensíveis. Na sua situação de fugitivo, o personagem apura os seus sentidos, começa a perceber sinais da natureza antes desprezados pela sua atividade limitada a lidar com dados numéricos, pois a verdadeira profissão de Martim era a de estatístico. No seu caminho de aprendizagem, além do alheamento proposital da convivência com os outros homens, o mundo passa a ser interpretado também pelos impulsos interiores.

No período em que vive na fazenda, Martim lida com o concreto através dos trabalhos braçais no campo, no depósito de lenha, na manutenção dos objetos, mas sempre escapa da realidade concreta pela potência do pensamento, imaginando e articulando suas reflexões. Nessa

\footnotetext{
${ }^{8}$ CASSIRER, Ernest. Ensaio sobre o homem. Introdução a uma filosofia da cultura humana. São Paulo: Martins Fontes, 2016, p. 73.
}

154 | D O S S I Ê : ROMANCE DE FORMAÇ̃̃O - CAMINHOS E DESCAMINHOS DO HERÓI 
realidade mais objetiva, ele tem o contato da linguagem interativa com Ermelinda e Vitória. Entretanto, como observou Benedito Nunes em "A maçã no escuro ou o drama da linguagem" ${ }^{\prime}$, esses diálogos mais distanciam do que aproximam esses personagens. Ainda assim temos explícitas as relações baseadas na articulação dos raciocínios e nos pontos de vista, mesmo divergentes em sua predominância.

Para escapar dessa concepção racional, Martim se aproxima mais uma vez do espaço da natureza, como no começo da narrativa. Os animais, as montanhas, as árvores, o vento, a terra, todas as manifestações advindas do que não é humano serão a ponte para uma realidade paralela à sua existência solitária. Durante sua trajetória ele se animaliza para também aprender sobre a existência, pois a linguagem humana não é suficiente para compreender o mundo corrente, que aos seus olhos perdeu a magia. Essa espécie de inversão da ordem dos saberes mantém, sob a nova chave exasperada do aprendizado da linguagem, a fissura sujeito-objeto cuja expressão, no romance, Lukács viu como forma do "desterro transcendental"10, e que Anatol Rosenfeld 11 encontrou na modernidade como "desrealização" das formas artísticas com o desmanche da perspectiva e do figurativismo.

Assim, na crise da modernidade em meados do século XX, os caminhos das personagens de Clarice Lispector serão colhidos pela interioridade. Ao limpar o curral pela primeira vez, Martim parece ter uma revelação. É nesse ambiente escuro, fétido e habitado pelos bichos que o homem se identifica com uma essência mais primitiva.

E, ofuscado, estacou. No começo nada viu, como quando se entra numa grota. Mas as vacas habituadas à obscuridade haviam percebido o estranho. E ele sentiu no corpo todo que seu corpo estava sendo experimentado pelas vacas: estas começaram a mugir devagar e moviam as patas sem ao menos olhá-lo - com aquela falta de necessidade de ver para saber que os animais têm, como se já tivessem atravessado a infinita extensão da própria subjetividade a ponto de alcançarem o outro lado: a perfeita objetividade que não precisa mais ser demonstrada [...]. Em júbilo trêmulo, o homem sentiu que alguma coisa enfim acontecera. Deu-lhe então uma aflição intensa como quando se é feliz e não se tem em que aplicar a felicidade, e se olha ao redor e não há como dar esse instante de felicidade. (p. 96).

\footnotetext{
${ }_{9}^{9}$ NUNES, Benedito. O drama da linguagem. Uma leitura de Clarice Lispector. São Paulo: Ática, 1995.

${ }^{10}$ LUKÁCS, Georg. A teoria do romance. Um ensaio histórico-filosófico sobre as formas da grande épica. Tradução, posfácio e notas de José Marcos Mariani de Macedo. São Paulo: Duas Cidades; Editora 34, 2000, p. 61, 127.

${ }^{11}$ ROSENFELD, Anatol. Reflexões sobre o romance moderno. In: Texto/Contexto. Ensaios. São Paulo: Perspectiva, 1985, p. 76.
}

155 | D O S S I Ê : ROMANCE DE FORMAÇ̃̃O - CAMINHOS E DESCAMINHOS DO HERÓI 
Martim vai realizando de modo contínuo os trabalhos na fazenda, como uma espécie de continuidade de sua fuga para não se aproximar de Vitória, da prima Ermelinda e dos outros empregados do lugar. Mas mesmo interagindo e aprendendo com os animais e o universo natural da fazenda, sente a necessidade da comunicação. Suas pretensões de isolamento são quebradas em muitos momentos, principalmente a partir da segunda parte do romance, "Nascimento do herói", em que ele recorda de momentos vividos com o filho pequeno, aproxima-se mais de Ermelinda e tem diálogos cada vez mais ásperos com Vitória. Tenta escrever quando está sozinho no depósito de lenha, mas a linguagem que elabora não tem como se desprender das estruturas que, pretensiosamente, intenciona superar, pois não há como comunicar sem se fazer entendido pelo outro. E esses outros estão estabelecidos numa vivência medida pela manutenção dos costumes. Como aponta Benedito Nunes ${ }^{12}$, esse herói rebelde, que foi gerado pela palavra transformadora, tem características de poeta e de apóstolo. É um infrator tanto do código moral, pelo seu crime, quanto do código linguístico, pois quer colocar-se acima da linguagem comum. Mas essa tarefa é impossível de ser cumprida pelo homem:

\begin{abstract}
Quando o homem releu a sua obra, já com os olhos piscando de sono, a realidade deu uma reviravolta, e ele se defrontou no papel com a concretização física e humilde de um pensamento, e teve um riso vazio e largo - onde pela primeira vez o senso do ridículo apareceu, solapando pela primeira vez a sua grandeza [...] esbarrou com o fato de que ele era apenas uma pessoa confusa que esquecera os livros que lera mas deles haviam ficado muitas imagens dúbias que ele perseguia, sua terminologia estava fora de moda, ele ficara nas suas primeiras leituras. (p. 178).
\end{abstract}

A inabilidade do homem para concretizar a dimensão experimental da linguagem em forma de função representativa revela, como de hábito, o caráter malogrado das ações dos protagonistas ao final dos romances de Clarice Lispector. O que foi exposto aqui em Perto do coração selvagem, com relação a Joana e sua tendência semiplena, ocorre com outras personagens, como Lucrécia, em A cidade sitiada. Nessa mesma trajetória de consternação se encontra Virgínia, em $O$ lustre, que ao final da narrativa encontra a morte. Em A paixão segundo G.H., esta revela uma experiência solitária dramática que não pode oferecer outra alternativa que não seja $o$ isolamento. Como uma das raras exceções na obra da escritora, temos a ausência de desfecho adverso em Uma aprendizagem ou o livro dos prazeres, obra muito insólita no percurso criativo da autora, repleta de clichês nos diálogos amorosos entre Lóri e Ulisses, quase insuportáveis pelo seu didatismo. E na novela A hora da estrela, a 'incompetência' de Macabéa para

12 NUNES, Benedito. O drama da linguagem. Uma leitura de Clarice Lispector. São Paulo: Ática, 1995 , p. 46.

156 | D O S S I E : ROMANCE DE FORMAÇ̃̃O - CAMINHOS E DESCAMINHOS DO HERÓI 
uma vida regrada por normas de conduta que visam à integração social já é anunciada de antemão pelo narrador, Rodrigo S.M..

Ainda em "O mundo humano do espaço e do tempo", Ernest Cassirer considera que o ser humano vive muito mais em função de suas dúvidas e temores, das ansiedades e esperanças com relação ao futuro. As lembranças, assim como as experiências no presente vivido não têm a mesma importância na totalidade do sujeito. Essa percepção do filósofo evidencia que a sensação de incerteza só existe na nossa condição, e esse aspecto está diretamente ligado à capacidade de pensar e elaborar formas de linguagem. Isso possibilita uma pretensa autonomia, assim como uma problemática sensação de domínio e superioridade mediante as outras formas de vida no mundo, mas em muitos momentos, essa mesma potencialidade é uma condenação pelo estado de expectativa gerado em torno de uma existência reflexiva.

Na última parte, "A maçã no escuro", é possível notar a ansiedade de Martim diante dos acontecimentos, pois ele vive sob tensão quanto ao futuro. A história que contou para conseguir ficar na fazenda sempre foi vista com suspeita por Vitória, que acabou cedendo aos pedidos de trabalho e abrigo feitos por ele, impressionada desde os primeiros momentos com a beleza e obstinação do homem. Mas para reprimir o amor que sentia pelo forasteiro, acaba entregando-o às autoridades, com a ajuda de um professor e do prefeito da cidade. Não deixa de ser simbólico, nessa trajetória de aprendizagem, que Martim seja levado à prisão por intermédio de um educador, que é retratado com uma postura conservadora e punitiva, e também pela maior autoridade da cidade, que representa o poder de fiscalizar alguma anormalidade nas terras de Vila Baixa.

Descoberto então o seu crime, a tentativa de matar a mulher, Martim segue agora para o castigo do Estado, legitimado pelas figuras repressivas dos dois policiais, para cumprir as normas de educação através da restrição de sua liberdade. Ele constata que não é possível consolidar a sua linguagem de oposição além da perspectiva da imaginação, que não é possível desligar-se da sociedade e das estruturas que a regulam. Agora para o herói fracassado só resta a desobediência no plano das ideias, disfarçada e silenciosa, como um simples homem impotente no embate com os poderes instituídos.

Mona Lisa Bezerra Teixeira é doutora pelo Departamento de Teoria Literária e Literatura Comparada da FFLCH-USP, com a tese Imagens da infância na obra de Clarice Lispector (2010). Contato: mona.lisabt@uol.com.br 